\title{
Exploration of BIM Technology Diffusion organizational model based on the transaction cost theory \\ TANG Xiaoling ${ }^{1, a}$, CHEN Qinjian ${ }^{1, b}$ \\ ${ }^{1}$ Xi'an University Of Architecture And Technology, Shanxi 710055, China \\ bccqqjj03@163.com
}

Keywords: BIM; technology diffusion; information delivery; Transaction costs; organizational model

\begin{abstract}
This paper first introduces the concept of BIM technology diffusion and the diffusion model; Then in BIM consolidation stage, because of BIM technology diffusion in BIM technology using information delivery activities, further put forward by lowering the cost of the "activity" to promote and protect the adoption of BIM technology and development of enterprises or organizations again; Finally based on Williamson's transaction cost theory, standing in the point of view of whole life cycle of a project, in different project contracting mode, with the organizational structure model were BIM technology diffusion in the process of "activity" to reduce costs, to achieve the effective diffusion of BIM technology.

BIM as support industrial upgrading of core technology, the construction industry in our country are put it as a key development project. Therefore, effective diffusion and application of BIM technology in the construction industry has become the domestic scholars present wide public concern over the issue. BIM technology diffusion involves the ability to use the building, especially for various BIM technology, makes the information delivery activities in the process of BIM technology diffusion research one of the key analysis of BIM technology diffusion mechanism, so that we can reduce the cost of the "activity" to promote and protect adopt BIM technology and development of enterprises or organizations again. In order to reduce the cost of the "activity", it is necessary to explore the organization mode of BIM technology diffusion.
\end{abstract}

\section{Summary of BIM technology diffusion}

Technology diffusion is a follow-up subprocesses in the process of innovation, but at the same time is a complex technology combined with economy, technology and market of the movement process. BIM technology as a new technology of visualization, collaborative, in the full life cycle of project planning, operation and maintenance of the process of sharing and transfer, through building the industrial chain each link to participate, to constantly replenish rich building data. As a result, the spread of the BIM technology refers to the modern computer network technology based on BIM technology, after a certain time, in the construction industry through the building economic ties between businesses, between construction enterprise and construction enterprise internal propagated and penetration process. And we put the BIM technology diffusion process is divided into two phases: construction enterprise technology adoption phase between and within the enterprise technology integration stage ${ }^{[1]}$.

According to the diffusion of innovation theory, BIM technology diffusion process can be divided into cognition, evaluation, decision-making, running-in, the implementation of five stages ${ }^{[2]}$, the process model is shown in figure 1. 


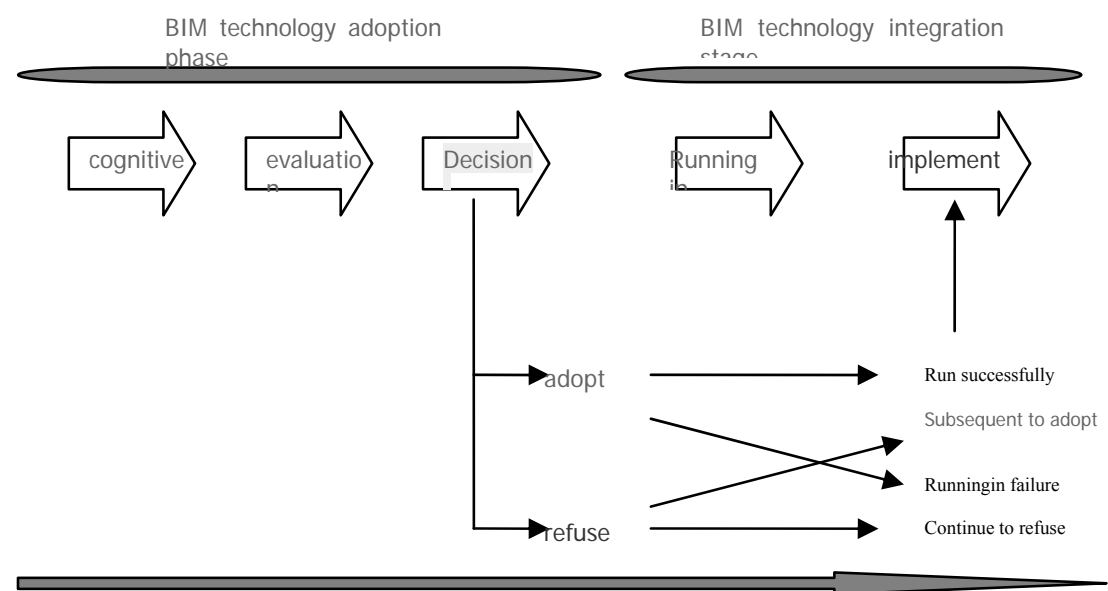

Figure 1 BIM technology diffusion model of the process

In order to achieve the success of BIM technology in the domestic construction industry, the key is to implement BIM technology and the successful integration of enterprise original workflow. The current our country is in BIM technology integration is the stage.

\section{BIM technology diffusion in the process of information delivery activities}

BIM technology diffusion involves the ability to use the building, especially for various BIM technology, makes the BIM technology diffusion in the process of information delivery activities become one of the key analysis of BIM technology diffusion mechanism research. Therefore, we further study the BIM deliverables when use technology in information delivery activity of property rights definition and workflow model of information delivery.

2.1 BIM technology diffusion of information property right definition

In BIM technology diffusion process, therefore, we define the information property right is in the process of BIM technology diffusion, the participants completed professional feedback to deliver content as the main carrier of information and ownership of deliverables include BIM model and use of BIM model directly generated drawings, tables, documents, and animation, etc. Such information in the property must be specific, identifiable; Information product has actual or potential use and exchange value, or have economic value and can be traded.

\subsection{Transaction cost theory}

BIM deliverables of the process of technology diffusion has the property of property rights, in order to reduce the transaction costs, in turn, promote the effective diffusion of BIM technology, we based on the theory of transaction cost analysis of BIM technology diffusion path.

According to Williamson's transaction cost theory, economic activity in the system running through all kinds of "activity" to sustain. In order to make efficient and effective trading activities, trading parties concerned shall establish all kinds of contractual relationship. In order to ensure the establishment of the contractual relationship and implementation of a series of activities and activity cost is inevitable. Therefore, BIM technology diffusion BIM model as the main carrier, clear the parties by means of contract delivery requirements, QuanZeLi boundary and model and information knowledge ownership problems, to reduce transaction cost, the purpose of protecting the interests of the parties.

2.3 Working process model of information delivery

In the whole life cycle of projects, BIM technology diffusion process will inevitably produce the transaction cost, yet transaction costs are hard to quantify. It seems to Williamson's transaction cost theory, transaction cost is defined from the perspective of contract use different organization and management structure of the cost, is because friction caused by the cost of the system. As a result, the BIM technology diffusion in the process of information delivery and project workflow definition clear is necessary, in reducing the transaction cost under the premise of we use flow diagram model describes BIM technology diffusion of an "activity" (for example, the design phase) work process of information delivery. 


\section{BIM technology diffusion of project organization mode}

Above one of the working process model of "activity" information delivery can maximum reduce project a "activity"(such as the design phase of information delivery fees), for the whole life cycle of a project, based on the transaction cost theory, the stand or fall of BIM technology diffusion of project organization mode can reflect the BIM technology diffusion time information delivery activities between transaction costs and can show the diffusion efficiency of BIM technology diffusion in the project.

3.1 BIM technology diffusion of project organization factors

BIM technology diffusion process, many factors influence the transmission path, therefore, to explore the project organization pattern of BIM technology diffusion must first clear is the main influencing factors.

(1) Participants in the main body

Including the owner, design, construction, operations, consulting, supervision party, software developers, etc. Specific performance for participation main body the cognitive level of BIM technology and support; To the operation of the BIM software level; Identification of the collaborative BIM platform sharing degree, etc.

(2) contracting mode

Project contracting mode choice depends on the number of the contractor, project management mode, organization mode, and the power of the contract parties, responsibility and task allocation is based on the dividing. Concrete consists of DBB model, DB mode, EPC mode, CM, Partnering, IPD mode, BOT mode, the PPP mode, etc.

(3) the BIM software platform for the development and construction

BIM technology in the construction industry is the basis of effective diffusion of BIM software development, the establishment of the digital resources plus.

(4) plus the cultivation of professional talents

BIM professionals can not only familiar with BIM software, also known as architectural engineering professional knowledge, only together to build the appropriate project organization model, gives the process at the time of delivery cost minimum, to achieve effective diffusion of BIM technology.

3.2 BIM technology diffusion of the construction of the project organization mode

Project contracting mode choice is project implementation strategy, is the important factors that affect the organization mode of the BIM technology diffusion. From the view point of reducing transaction costs, the application of BIM technology project contracting mode choice process integrated contracting mode and mutual cooperation contracting mode ${ }^{[3]}$. From under the two kinds of representative EPC mode and the IPD mode to explore the organization mode of BIM technology diffusion.

(1) EPC mode BIM technology diffusion model of project organization

Forms of EPC (Engineering Procurement Construction), the comprehensive pattern design, Procurement, Construction, the total contracting contract mode compared with the traditional contracting mode, contractor will design and purchasing two links for the integrated contracting, and not just for Construction activities. Thus for design and construction of the model can be overcome, the contradiction of the separate owners do not need to consider the concrete design, construction and procurement, the specific work to a unit of EPC contractor is responsible to, overall contractor to owner finally provide complete design blueprint and construction results. This model greatly reduces the pressure for the management of the owner.

In EPC mode study BIM technology diffusion mode of organization, to ensure that each participation main body, each management function, the subcontractor's information must be unified into BIM database platform, the ultimate decision makers by the project summary after share to each participation main body. Therefore, we select matrix organizational structure to express the BIM technology diffusion path, in order to reduce transaction costs.

In EPC mode, matrix project organization model is transverse BIM technology in project project management function and the longitudinal effective integration of each participation main body 
process work, the greatest degree of reducing transaction cost the total project life cycle information delivery. Embodied in transverse project management function of each project management function through the BIM platform to collect information, vertical each participation main body through the BIM platform in collecting all kinds of corresponding phases of the project engineering project information, information through the matrix organization structure on BIM platform convergence integration. Eventually the information under the leadership of the BIM program director of the plan as a whole summary into BIM database integration and be updated constantly perfect the information basis of BIM model.

(2) the IPD mode BIM technology diffusion model of project organization

IPD mode (Integrated Project Delivery). This mode by integrating project system, manpower, practice and enterprise structure for a unified process, through the BIM collaboration platform, make full use of each participation main body insights and talent, through the cooperation of the total project life cycle stages, the maximum benefits of the construction project, increase the value of the project owner, reduce waste, to optimize the project delivery process of each process, reduce the transaction cost when information delivery mode of project delivery.

In IPD mode, the project of the main stakeholders involved in the early years of the project, the project team and through the IPD contract form a contractual relationship, the owners, engineers, contractors, and other possible projects established a cooperative relationship between related parties, so that the benefits and risks of the consistent ${ }^{[4]}$. The model need a adapt to the knowledge society, information economy collaboration and sharing as the goal, the information flow as the driving force of organization, therefore, we select network organization structure to express the path of BIM information collection and sharing, which reflects the spread of BIM technology diffusion path and integrated form.

\section{Conclusion}

According to the diffusion of innovation theory, this paper builds BIM technology diffusion process model, and points out that the current phase should focus on BIM technology integration. Because of BIM technology diffusion in BIM technology using information delivery activities, further put forward by lowering the cost of the "activity" to promote and protect the adoption of BIM technology and development of enterprises or organizations again; Then based on the theory of transaction cost, standing in the Angle of the total project life cycle, to reduce transaction costs, in different contracting mode to explore the best organization mode of BIM technology diffusion, finally found in EPC mode matrix organizational structure and in the IPD mode of network organization structure. This paper is a supplement to the BIM delivery requirements in the standard, to delve into BIM technology diffusion caused by virtual cluster do bedding, is conducive to the effective diffusion of BIM technology in the construction industry and the development of the construction of informatization in our country.

\section{Reference}

[1]Tang Xiaoling, Tian Chenxi. Building information model (BIM) technology diffusion and application [J]. Journal of building economy, 2013 (6) : 99.

[2]Prahalad, chai zhang. The process of technology diffusion and model: a literature review [J]. Journal of central south university, 2013, 12 (4) : 15 to 16.

[3]Wang Maoxin. Trading mode choice and innovation research project [D]. Chongqing university, 2014.

[4]Lian-ying zhang, LuanYan. IPD trading mode of the project cost control [J]. Journal of international economic cooperation, 2010 (11) : 69-70. 